\title{
O jogo do bufão como ferramenta para o artivista
}

\author{
Vanessa Benites Bordin \\ Mestranda em Artes Cênicas/USP \\ Área de Concentração: Pedagogia do Teatro \\ Orientadora: Elisabeth Silva Lopes \\ Atriz e arte-educadora
}

Resumo: o presente projeto tem como eixo a relação entre a prática artística e política do ator/performer. A partir da pesquisa com o bufão, busco analisar a eficácia de seu jogo na realização de ações políticas, em lugares cênicos ou públicos. Este estudo, que se insere no campo da performance política, circunscreve essa investigação na esfera do grotesco cômico popular. Sendo assim, centrado no caráter de denúncia e protesto do bufão, examino os jogos de paródia e blasfêmia que endereçam suas críticas e ações sempre em favor da liberdade. Comparando a gestualidade crítica do bufão com a do homem que grafita, por exemplo, examino os trabalhos de "artivistas", como Reverend Billy e Guillermo Gómez-Peña, que se utilizam do grotesco, da ironia e da bufonaria para denunciar as injustiças contra o homem na sociedade capitalista.

Palavras-chave: ativismo, bufonaria, popular

Title: The jester's game as a tool for artivists

Abstract: this Project has as its axis the relationship between artistic practice and politics of the actor/performer. From the research I seek to analyze the buffoon with the effectiveness of his play in carrying out political actions in public places or scenic. This study, which belongs to the field of political performance, limited its research in this sphere of popular comic grotesque. Thus, focusing on the character of complaint and protest buffoon, I examine the play of parody and blasphemy that address their criticisms and actions always in favor of freedom. Comparing the critical gesture of buffoon with the man who graphite, for example, I examine the works of "artivists" as Reverend Billy and Guillermo Gómez-Peña who use the grotesque, irony and buffoonery to denounce the injustices against the man in capitalist society.

Keywords: activism, buffoonery, popular

Título: El juego de bufón como herramienta para el artivista

Resumen: este proyecto tiene como eje la relación entre la práctica artística y política del actor/performer. A partir de la investigación con el bufón busco analizar la eficacia de su juego en la realización de acciones políticas en lugares públicos o escénicos. Este estudio, que pertenece al ámbito de performance política, pone la investigación en el ámbito de lo grotesco cómico popular. Por lo tanto, se centra en el carácter de denuncia y protesta del bufón, examino los juegos de parodia y blasfemia que dirigen sus críticas y acciones siempre a favor de la libertad. Comparando el gesto crítico del bufón con el del hombre que hace grafitis, por ejemplo, examino las obras de "artivistas" como el Reverend Billy y Guillermo Gómez-Peña que se valen de lo grotesco, de la ironía y de la bufonada para denunciar las injusticias contra el hombre en la sociedad capitalista.

Palabras-clave: activismo, bufonería, popular 
Essa pesquisa, que está em sua fase inicial, propõe uma relação dialógica entre teoria e prática, refletindo sobre as influências do grotesco cômico popular, tendo como referência a figura do bufão para o trabalho do ator que realiza ações artísticas com fins políticos, colocando-se como ativista. O método experimental dedutivo servirá para se chegar ao foco principal do trabalho a partir do que foi pesquisado.

Ligado ao grotesco cômico popular, por apresentar o exagero, a deformidade e provocar o riso da paródia, o bufão foi o porta voz da cultura cômica popular. O grotesco é analisado por Mikhail Bakhtin, que examina as diferentes manifestações da cultura popular da Idade Média e do Renascimento, a partir do contexto da obra de François Rabelais. Bakhtin aborda a questão do realismo grotesco, como sendo o sistema de imagens da cultura cômica popular, analisado a partir da dupla visão de mundo medieval. Essa dualidade na visão de mundo, que para ele é inerente à civilização do homem, se divide da seguinte maneira: de um lado, a visão oficial e religiosa, configurada pelos valores da sociedade feudal; de outro, a visão não oficial, representada pela cultura cômica popular, com seu caráter festivo, carnavalesco, invertendo a ordem social:

A dualidade na percepção do mundo e da vida já existia no estágio anterior da civilização primitiva. No folclore dos povos primitivos encontra-se, paralelamente aos cultos sérios (por sua organização e seu tom), a existência de cultos cômicos, que convertiam as divindades em objetos de burla e blasfêmia ("riso ritual"); paralelamente aos mitos sérios, mitos cômicos e injuriosos; paralelamente aos heróis, seus sósias paródicos (BAKHTIN, 1993, p. 5).

A visão não oficial produz um mundo "às avessas" (BAKHTIN, 1993), característico das festas populares e principalmente do carnaval - que é visto como a segunda vida do povo, ou sua vida festiva. De acordo com Bakhtin, essa vida festiva leva a uma inversão hierárquica e tem o realismo grotesco como um instrumento de análise para entender essas relações.

Durante a Idade Média, o caráter popular e festivo do grotesco, aparece em manifestações da cultura popular como o carnaval, a festa do asno e a festa dos loucos, que aconteciam durante as comemorações do nascimento, morte e ressurreição de Jesus Cristo. Embora essas festas estivessem fora do mundo oficial, elas eram autorizadas e serviam para inverter a ordem estabelecida. No período medieval e renascentista o carnaval não era visto com um espetáculo, mas como uma forma concreta da vida, mesmo que por um curto período de tempo. A carnavalização do mundo, para o realismo grotesco, possibilita uma visão crítica desse mundo, onde se eliminam as hierarquias entre os homens, promovendo a inversão de papéis sociais e com isso possibilitando novas relações entre eles. 
[...] na realidade, a função do grotesco é liberar o homem das formas de necessidade inumana em que se baseiam as ideias dominantes sobre o mundo. $\mathrm{O}$ grotesco derruba essa necessidade e descobre seu caráter relativo e limitado. A necessidade apresenta-se num determinado momento como algo sério, incondicional e peremptório. Mas historicamente as ideias de necessidade são sempre relativas e versáteis. O riso e a visão carnavalesca do mundo, que estão na base do grotesco destroem a seriedade unilateral e as pretensões de significação incondicional e intemporal e liberam a consciência, o pensamento e a imaginação humana, que ficam assim disponíveis para o desenvolvimento de novas possibilidades. (BAKHTIN, 1993, p. 43)

O caráter sério da Idade Média possibilitava a difusão do riso de libertação, tendo na figura do bufão o principal elemento da época a trazer a tona esse riso degradante, realizando a paródia através da linguagem blasfematória. A linguagem carnavalesca do grotesco é caracterizada por apresentar a ambivalência do mundo, que está presente no que Bakhtin chama de "princípio material e corporal", que configura a consciência do "baixo" em contradição com o "alto". O "baixo" é representado pelos órgãos sexuais, ou seja, a necessidade carnal e o contato com a terra. O "alto" simboliza o céu, a cabeça, ou seja, a razão. Os dois elementos seriam a fusão entre o sagrado e o profano. Esse princípio se complementa com a "linguagem da praça pública" (BAKHTIN, 1993) que se utiliza de injúrias e grosserias. Também caracterizado pelo exagero, pela deformação, tendo como porta-voz a figura do bufão, do bobo, que traz em seu corpo o grotesco do "princípio material e corporal":

As formas do cômico popular da praça pública constituíam também uma das fontes importantes da imagem grotesca do corpo. Só podemos passar em revista, rapidamente, esse mundo tão vasto e variado. Todos esses acrobatas, funâmbulos e triagueiros, etc., eram atletas, prestidigitadores, bufões, apresentadores de macacos (réplicas grotescas do homem), vendedores de panacéias universais. O universo das formas cômicas que eles cultivavam era o universo do corpo grotesco nitidamente expresso. Hoje ainda, é nos espetáculos de feira e num grau menor no circo, que o corpo grotesco se conserva melhor. (BAKHTIN, 1993, p. 309).

No período de festas medievais, era liberado o uso de grosserias, palavrões, xingamentos. É a "linguagem familiar da praça pública", que está diretamente ligada ao "princípio material e corporal" do realismo grotesco, com seu apogeu na cultura popular durante a Idade Média e o Renascimento, representando a fertilidade e abundância. Nesse princípio está presente a visão do mundo a partir do "baixo material e corporal" (BAKHTIN, 1993), partindo da ideia de rebaixamento de tudo que é elevado e espiritual para o plano da terra e do corpo, revelando o riso grotesco da época, em que ocorre a fusão do sério com o cômico. 
Diversos pesquisadores do campo teatral retomam a figura do bufão para desenvolver seu trabalho, analisando a relevância em resgatar as origens do popular, especificamente falando-se da "máscara grotesca utilizada pelo ator popular (LOPES, 2005, p. 13) buscada no século XX por encenadores que pensavam em um teatro crítico, como Brecht. ${ }^{1}$ A pesquisadora Elisabeth Lopes (2005) aborda o tema em seu artigo A blasfêmia, o prazer, o incorreto. Esse resgate das origens populares, diz respeito ao caráter grotesco encontrado nas manifestações teatrais populares cômicas que aconteciam em feiras ambulantes. Percebeu-se que essas formas de representação conseguiam despertar o interesse do público devido a sua grande capacidade de improvisação e espontaneidade. Assim esses encenadores buscaram o grotesco do teatro popular em sua prática teatral.

Para eles a máscara se impõe como símbolo do jogo do ator e o grotesco, sugerindo gestos exagerados e distantes das ações cotidianas, dá à expressão teatral um sentido dialético. A força da gestualidade e da voz grotesca seria a tônica do modo de atuar dos atores dos movimentos de vanguarda da virada do século, o Expressionismo, e depois, o Futurismo, Dadaísmo e Surrealismo. (LOPES, 2005, p. 14)

No caso da obra de Bertolt Brecht, o grotesco aparece com a retomada das tradições do realismo grotesco e da cultura popular, por influência do cômico popular Karl Valentin, do teatro de feira e do cabaré alemão. A maneira de representar de Karl Valentin dá a Brecht às premissas básicas do trabalho prático para o ator de seu teatro épico:

Era um jovem quando a primeira guerra mundial acabou. Estava a estudar medicina na Alemanha do Sul. As suas principais influências eram dois escritores e um palhaço popular. [...] Mas com quem aprendia mais era com o palhaço Valentin, que se apresentava numa cervejaria. Representava, em breves cenas, empregados renitentes, músicos de orquestra ou fotógrafos que odiavam os seus patrões e os ridicularizavam. $\mathrm{O}$ papel do patrão era feito, pela sua assistente, uma cômica popular, que cingia uma barriga artificial e falava de voz grossa (BRECHT, 1999, p. 35).

Utiliza-se do tom irônico e grotesco da bufonaria para revelar os problemas sociais, políticos e econômicos de sua época, fazendo a crítica dentro do aparelho teatral burguês. Brecht encontra na arte cômica popular e no teatro oriental uma característica que seria fundamental no desenvolvimento de seu trabalho, o efeito de distanciamento ou efeito V (Verfremdungseffekt). Para ele, novo modelo de teatro, o teatro épico, necessita do efeito de distanciamento para realizar a crítica social e tornar históricos os fatos apresentados em cena:

Esta tentativa de distanciar do público os acontecimentos representados manifesta-se já, em grau primitivo, nas obras teatrais e pictóricas apresentadas nas 
tradicionais feiras anuais. $\mathrm{O}$ modo como fala o palhaço do circo e o modo como estão pintados os panoramas ${ }^{2}$ acusam a utilização do ato de distanciamento (BRECHT, 2005, p. 75-76).

O efeito de distanciamento tem o intuito de provocar uma tomada de posição do espectador que não seja através da identificação, mas sim, do questionamento diante da situação apresentada, distanciando-se dela, possibilitando a formação de um pensamento crítico por parte do público. Assim, o ator do teatro de Brecht coloca sua visão crítica, junto da do personagem e do espectador, produzindo com isso o efeito de distanciamento, no intuito de obter a transformação social, adotando uma perspectiva "crítico-social" (BRECHT, 2005, p. 109).

$\mathrm{Na}$ atualidade, encontram-se múltiplas manifestações artísticas, políticas e culturais que visam realizar a crítica social, no entanto com a invasão midiática que cresce a cada dia banalizando essas formas de intervenção - muitas vezes elas se tornam reacionárias, ao invés de revolucionárias, aceitas e aplaudidas por esse mesmo sistema que desejam criticar. Assim, pretendese refletir sobre a pichação, uma forma de intervenção crítica, no entanto, marginalizada por não ser interpretada positivamente por grande parte da população, fazendo uma relação com o espírito de denúncia presente na bufonaria.

Em sua pedagogia da criação teatral, Jacques Lecoq ${ }^{3}$ compara a gestualidade crítica do bufão com a do homem que grafita "abaixo as armas" nas paredes dos banheiros (LECOQ, 2010, p. 32) como uma forma de protesto. Ambos desafiam condutas, normas e preceitos da sociedade, realizando uma crítica que busca denunciar as injustiças sociais e interferir nas políticas governamentais. Para isso, apropriam-se de elementos grotescos e derrisórios.

Neste caso, a analogia entre o bufão e o grafiteiro se evidencia como um conceito ligado à denúncia, ao protesto e às ações que se declaram pela liberdade de expressão. Os recursos grotescos se constituem como procedimentos que envolvem uma deliberada crítica social, denunciando com a blasfêmia e a paródia as pessoas com suas convicções mais profundas e equivocadas. Assim, as pichações que se encontram nas ruas de qualquer cidade nos fazem refletir sobre suas inscrições, desenhos e pinturas como manifestos. Estas inscrições, cuja expressão se desdobra em inúmeros significados, como as formas grotescas primitivas das cavernas com seus arabescos, criam um jogo de contraposições, de formas contínuas e infinitas.

A arquitetura das igrejas e dos edifícios que erguem as instituições públicas ou privadas servem de suporte para caricaturas, pinturas, frases, palavras que denunciam e revelam o pensamento de anônimos ao coletivo. 
O que está em jogo no grotesco incorporado por aquele que grafita relacionado à bufonaria é a distorção das imagens reais, pois se apropriam de imagens cotidianas, deformando-as, com o intuito de criticá-las. Assim, através dessa distorção da realidade conseguem mostrar o que está por trás daquilo que é tido como habitual. A pichação representa um ato de bufonaria por acusar práticas sociais que muitas vezes estão encobertas ou se apresentam corruptamente para a maioria da população, utilizando-se para isso de textos e/ou imagens que denunciam, questionam ou simplesmente relatam tais fatos, agindo como um grito de alerta para os passantes das ruas, informado-os ou instigando-os a refletir à respeito.

Entre os pichadores há um código com regras próprias, assim como o bufão faz parte de um mundo onde estabelece suas próprias regras, freqüentemente divergentes de algumas regras sociais vigentes. O grotesco da pichação pode ser caracterizado em sua forma de interagir nos espaços urbanos, realizando a crítica social por meio de uma linguagem considerada pelo sistema vigente como agressiva, feia, marginalizada e responsável por poluir estes espaços.

No entanto, o que se pode perceber é que essa manifestação se coloca em contraponto a um espaço público que já está invadido por diversas manifestações artísticas, publicitárias e também políticas. No Brasil e em muitos países, essa prática é proibida e considerada crime de degradação ao patrimônio público e privado. Contudo, deve-se considerar o bombardeio de imagens que nos são impostas por uma cultura capitalista que visa o consumo excessivo, por exemplo a propaganda, que invade desde lugares de difícil acesso até grandes metrópoles, tornando-se onipresente.

\footnotetext{
O objetivo de observar o poder invasivo, contido na pichação como um signo urbano, é de a relacionar a outras manifestações visuais entorno do diálogo criado com o habitante citadino. Em um comparativo com a publicidade, por exemplo, percebe-se que, enquanto uma goza de legitimidade autorizada, mediante pagamento, a outra é institucionalmente ilegítima, e sua realização está sujeita à pena e/ou ao pagamento de multa. As razões para essa diferenciação podem ser encontradas nos artigo da legislação brasileira ou então nos meandros do sistema capitalista internacional (SPINELLI, 2007).
}

A sociedade, falando-se em um sentido moral e cultural, não vê o pichador com bons olhos, denominando-os delinquentes e, desse modo, marginalizando-os. Isso ocorre principalmente com os jovens que vivem na periferia das cidades. Eles acabam sendo estigmatizados pela sociedade elitista como bandidos e culpados por poluir visualmente a cidade. $\mathrm{O}$ fato destes jovens viverem nas periferias dificulta seu acesso à infraestrutura oferecida pela cidade, que se concentra nas regiões centrais; isso acaba contribuindo para sua exclusão. Deste modo, acredita-se que o 
pichador quando intervém nas edificações da cidade não tem o objetivo de poluí-la visualmente, mas afirmar sua presença em uma disputa por visibilidade dentro do ambiente urbano.

Percebe-se no fato dos pichadores se utilizarem de espaços urbanos visíveis para expor seus pensamentos um espelho da maneira de reproduzir os mesmos modelos de comunicação nos quais foram ensinados. Portanto, ao expressarem-se junto dos painéis de propagandas publicitárias, tentam se tornar visíveis dentro do sistema urbano no qual estão inseridos, mas ao mesmo tempo do qual não tem acesso para usufruir completamente.

O caráter grotesco da crítica social que denuncia, contido nas manifestações dos pichadores da periferia, assim como na bufonaria, se dá pelo uso de uma linguagem provocativa, que visa à denúncia de injustiças sociais e convicções moralistas. As armas de crítica utilizadas por eles são julgadas agressivas, marginais e também podem ser consideradas ilícitas; no entanto, são as que estão ao seu alcance para se fazer notar dentro da sociedade.

Essa gestualidade crítica do bufão contida nos atos de pichação também é encontrada nos trabalhos de Reverend Billy e Guillermo Gomez-Peña, artistas que tem uma postura ativista. Para designá-los, vamos usar aqui o termo artivista.

O termo artivista é um neologismo sugerido por Laura Baigorri ${ }^{4}$ para se referir à arte de caráter ativista com preocupações políticas e de resistência cultural. O que nos interessa neste estudo é a análise de práticas artísticas coletivas que se articulam como ativismo ou modos de envolvimento político numa integração ativa entre arte e vida. Os dois artistas pretendidos na pesquisa têm essa integração ativista entre arte e vida, utilizando-se do jogo de paródia e denúncia do bufão.

Guillermo Gómez-Peña com seu grupo La Pocha Nostra, localizado em Los Angeles, nos Estados Unidos, assume uma postura antinacionalista, busca eliminar barreiras entre arte e política, raça e gênero. Sua opinião com relação à colonização é que ela aparece como um resultado do hibridismo cultural. Guillermo para realizar a crítica usa a paródia pelo estereótipo do colonizado, brinca com o clichê fazendo uma crítica da própria visão que se tem dos latinos que invadem a América, essas pessoas sem territórios.

Reverend Billy aparece como um bufão profeta, que com sua pregação, criticando a igreja evangélica, cria sua própria igreja, com uma representativa quantidade de fiéis. Assim, busca questionar as questões da cidade, como a economia transnacional, as grandes corporações, o poder do petróleo, utilizando-se da blasfêmia e da paródia com seu humor sarcástico. 
A partir da reivindicação da utilização dos espaços públicos que antes eram de passagem e hoje exploram e escravizam seus empregados, Reverend Billy se usa da ironia e da provocação como forma do discurso, utilizando o espaço da rua com multidões.

\section{Referências}

BAIGORRI, Laura (2003). Recapitulando: modelos de artivismo (1994-2003). Artnodes, UOC, 2003. Disponível em: http://www.uoc.edu/artnodes/espai/esp/art/baigorri0803/baigorri0803.html

BAKHTIN, Mikhail. A cultura popular na idade média e no renascimento: o contexto de François Rabelais. São Paulo: Hucitec, 1993.

BRECHT, Bertolt. A compra do latão. Lisboa: Vega, 1999.

. Estudos sobre teatro. Rio de Janeiro: Nova Fronteira, 2005.

CAVALIÈRE, Arlete. O inspetor geral de Gógol. São Paulo: Perspectiva, 1996.

ECO, Umberto. História da feiúra. Rio de Janeiro: Record, 2007.

FO, Dario. Manual mínimo do ator. 3. ed. São Paulo: SENAC, 2004.

GÓMEZ-PEÑA, Guillermo. Culturas-in-extremis: performing against the cultural backdrop of the mainstream bizarre. Edition by Henry Bial. Nova York: Routledge, 2004.

KAYSER, Wolfgang. O grotesco. São Paulo: Perspectiva. 2009.

LANE, Jill. Reverend Billy: preaching, protest and post-industrial flânerie. Edition by Henry Bial. Nova York: Routledge, 2004.

LOPES, Elisabeth Silva. A blasfêmia, o prazer, o incorreto. Sala Preta, São Paulo, Escola de Comunicações e Artes, Universidade de São Paulo, n. 5, p. 9-21, 2005.

LOPES, Elisabeth Silva. Encenação de pecados. Caderno de Literatura e Cultura Russa, 2010.

MINOIS, Georges. História do riso e do escárnio. São Paulo: Unesp, 2003.

OLSEN, Mark. As máscaras mutáveis do buda dourado. São Paulo: Perspectiva, 2004.

SPINELLI, Luciano. Pichação e Comunicação: um código sem regras. Revista Logos, n. 26, jan./jul. 2007. 
Revista "AspaS" - № 1 - 2011 - Anais do Primeiro Seminário de Pesquisas em Andamento ppgac do Programa de Pós-Graduação em Artes Cênicas da Universidade de São Paulo.

\footnotetext{
${ }^{1}$ Realizadores da arte teatral que desenvolveram seus trabalhos no inicio do século XX: Meyerhold na Rússia e Brecht na Alemanha.

${ }^{2}$ Designação de certas barracas de feira que apresentam motivos pictóricos dispostos panoramicamente. (Nota do autor)

${ }^{3}$ Ator, mimo e professor de teatro francês.

${ }^{4}$ Professora especialista em artes e novos meios na Faculdade de Belas Artes da Universidade de Barcelona.
} 